\title{
KARAKTERISTIK PERITONITIS PERFORASI ORGAN BERONGGA DI RSUD CUT MEUTIA ACEH UTARA
}

\author{
Muhammad Sayuti ${ }^{1}$ \\ ${ }^{1}$ Bagian Ilmu Bedah, Fakultas Kedokteran, Universitas Malikussaleh \\ Corresponding author: sayuti.md@unimal.ac.id
}

\begin{abstract}
Abstrak
Peritonitis adalah inflamasi peritoneum yang dapat terjadi karena kontaminasi mikroorganisme dalam rongga peritoneum, bahan kimiawi, atau keduanya. Peritonitis merupakan komplikasi berbahaya yang sering terjadi akibat penyebaran infeksi dari organorgan abdomen. Peritonitis masih merupakan masalah yang besar karena angka mortalitas dan morbilitasnya tinggi termasuk di Indonesia. Manajemen terapi yang tidak adekuat bisa berakibat fatal. Keputusan untuk melakukan tindakan bedah harus segera diambil karena setiap keterlambatan akan menimbulkan komplikasi yang semakin berat. Pemberian antibiotik dan terapi penunjang lainnya diberikan guna mencegah komplikasi sekunder yang mungkin terjadi. Penelitian ini bertujuan untuk mengetahui gambaran penyakit peritonitis perforasi terhadap penyebab dan pengobatanya di Cut Meutia Aceh Utara. Penelitian ini merupakan penelitan deskriptif retrospektif terhadap 45 sampel yang memenuhi kriteria inklusi dan eksklusi. Sampel diambil dengan teknik total sampling. Hasil penelitian menunjukkan berdasarkan jenis kelamin pasien laki-laki di dapatkan lebih banyak 30 orang $(66,6 \%)$. Berdasarkan usia terbanyak berada pada kelompok usia 40-60 tahun sebanyak 18 orang $(40 \%)$. Berdasarkan etiologi Peritonitis perforasi, appendisitis perforasi merupakan penyebab terbanyak 20 orang $(44,4 \%)$. Berdasarkan manifestasi klinis nyeri perut diderita 45 orang $(100 \%)$ dan menjadi manifestasi tersering yang dialami. Berdasarkan tindakan operatif Laparotomy eksplorasi dengan apendektomi merupakan tindakan terbanyak dilakukan ke 20 orang $(44,4 \%)$. Berdasarkan post operatif komplikasi menujukan bahwa tidak ada komplikasi yang berarti pada pasien sebanyak 37 orang $(82,2 \%)$. Berdasarkan lama rawatan menunjukan 4-7 hari merupakan waktu yang dibutuhkan untuk pasien pulang sebanyak 24 orang $(53,4 \%)$.
\end{abstract}

Kata Kunci : peritonitis; peritonitis perforasi.

\section{Cause And Treatment Outcome Of Perforation Peritonitis In Rural General Hospital Meutia Aceh Utara}

\begin{abstract}
Peritonitis is peritoneal inflammation that can occur because contamination microorganisms in peritoneal cavity, ingredient chemical, or both of them. Peritonitis is complications dangerous often occur consequence spread infection from the abdominal organs. Peritonitis still is a big problem because number mortality and his morbidity high including in Indonesia. Management therapy that is not adequate can fatal. Decision to do action surgical must immediately was taken because every tardiness will give rise to increasingly complications heavy. Antibiotics and therapy support the other was given to use prevent complications secondary possible happened. This study aims to find out the picture perforated peritonitis to cause and the treatment at Cut Meutia Aceh Utara. This research is a descriptive research retrospectively of 45 samples that met the inclusion and exclusion criteria. Samples were taken by total sampling technique. The results of the research show by
\end{abstract}


sex patient man get more many 30 people $(66.6 \%)$. By age the most are on on group age $40-$ 60 years as many as 18 people $(40 \%)$. Based etiology peritonation peritonitis, appendicitis perforation is a cause mostly 20 people $(44,4 \%)$. Based manifestation clinical pain stomach suffered 45 people $(100 \%)$ and to be manifestation the most experienced. Based action operative laparotomy exploration with appendectomy is a action a lot do to 20 people $(44,4$ $\%$ ). Based on post operatives complications address that not there is meaningful complications on patient as many as 37 people $(82,2 \%)$. Based on length of stay show 4-7 days is a time needed to patient return as many as 24 people $(53.4 \%)$.

\section{Keywords: peritonitis; peritonitis perforation.}

\section{PENDAHULUAN}

Peritonitis adalah inflamasi peritoneum yang dapat terjadi karena kontaminasi mikroorganisme dalam rongga peritoneum, bahan kimiawi, atau keduanya. ${ }^{(1)}$ Peritonitis merupakan komplikasi berbahaya yang sering terjadi akibat penyebaran infeksi dari organorgan abdomen. ${ }^{(2)}$ Menurut survei World Health Organization (WHO), angka mortalitas peritonitis mencapai 5,9 juta per tahun dengan angka kematian 9661 ribu orang meninggal. Negara tertinggi yang menderita penyakit ini adalah Amerika Serikat dengan penderita sebanyak 1.661 penderita. ${ }^{(3)}$ Hasil survey yang dilakukan pada tahun 2015 angka kejadian peritonitis masih tinggi. Di Indonesia jumlah penderita peritonitis berjumlah sekitar $9 \%$ dari jumlah penduduk atau sekitar 179.000 penderita. ${ }^{(4)}$ Peritonitis salah satu penyebab kematian tersering pada penderita bedah dengan mortalitas sebesar 10-40\%. Beberapa penelitian menunjukan angka mortalitas di Indonesia mencapai $60 \%$ bahkan lebih. ${ }^{(1)}$

Peritonitis dapat diklasifikasikan menjadi peritonitis primer, peritonitis sekunder, dan peritonitis tersier. Peritonitis primer disebabkan oleh penyebaran infeksi melalui darah dan kelenjar getah bening di peritoneum dan sering dikaitkan dengan penyakit sirosis hepatis. Peritonitis sekunder disebabkan oleh infeksi pada peritoneum yang berasal dari traktus gastrointestinal yang merupakan jenis peritonitis yang paling sering terjadi. Peritonitis tersier merupakan peritonitis yang disebabkan oleh iritan langsung yang sering terjadi pada pasien imunokompromais dan orang-orang dengan kondisi komorbid. ${ }^{(5)}$ Peritonitis perforasi organ berongga merupakan peritonitis sekunder akibat adanya perforasi di gastrointestinal tract.

Peritonitis masih merupakan masalah yang besar karena angka mortalitas dan morbilitasnya tinggi termasuk di Indonesia. Manajemen terapi yang tidak adekuat bisa berakibat fatal. ${ }^{(6)}$ Keputusan untuk melakukan tindakan bedah harus segera diambil karena setiap keterlambatan akan menimbulkan komplikasi yang semakin berat. Pemberian antibiotik dan terapi penunjang lainnya diberikan guna mencegah komplikasi sekunder yang mungkin terjadi. Tujuan dari pemberian antibiotik ini untuk membunuh bakteri yang ada di rongga peritonium maupun dalam sirkulasi. ${ }^{(3)}$ 
Penelitian ini bertujuan untuk meninjau penyebab dan hasil pengobatan peritonitis perforasi organ berongga di Rumah Sakit Umum Cut Meutia Aceh Utara periode Januari 2017-Desember 2018.

\section{METODE}

Penelitian ini merupakan jenis penelitian deskriptif retrospektif.

\section{Populasi dan Sampel Penelitian}

Populasi dalam penelitian ini adalah pasien dengan diagnosis peritonitis perforasi. Besar sampel penelitian ditentukan dengan mengunakan rumus total sampling, didapatkan jumlah sampel sebesar 45 orang.

1. Kriteria inklusi

a. Data rekam medik pasien peritonitis perforasi di RSUD Cut Meutia Aceh Utara periode Januari 2017-Desember 2018.

2. Kriteria eksklusi

a. Data yang tidak lengkap.

\section{Teknik pengambilan sampel}

Pengambilan sampel dilakukan dengan metode total sampling.

\section{Variable penelitian}

Variable dalam penelitian ini adalah Peritonitis perforasi.

\section{Instrumen penelitian}

Data rekam medik peritonitis perforasi di RSUD Cut Meutia Aceh Utara dan dokumentasi penelitian.

\section{Analisis data}

Analisis univariat untuk menggambarkan distribusi frekuensi variabel dependen. Data yang diperoleh dari hasil kuesioner dicatat dan dikumpulkan, kemudian disajikan dalam bentuk tabel distribusi frekuensi.

\section{HASIL PENELITIAN}

Penelitian ini didapatkan hasil yang dapat dilihat dalam tabel berikut

Tabel 1. Karakteristik Pasien Peritonitis Perforasi Berdasarkan Jenis Kelamin

\begin{tabular}{lcc}
\hline Jenis Kelamin & Frekuensi (n) & Persentase (\%) \\
\hline Laki-Laki & 30 & 66,6 \\
Perempuan & 15 & 33,4 \\
\hline Total & 45 & 100.0 \\
\hline
\end{tabular}


Tabel 1. Menunjukkan pasien yang terdiagnosa peritonitis perforasi lebih banyak pada lakilaki dengan jumlah 30 orang $(66,6 \%)$.

Tabel 2. Karakteristik Pasien Peritonitis Perforasi Berdasarkan Usia

\begin{tabular}{lcc}
\hline Usia & Frekuensi $(\mathrm{n})$ & Persentase $(\%)$ \\
\hline$<20$ tahun & 3 & 6,6 \\
$20-40$ tahun & 7 & 15,6 \\
$40-60$ tahun & 18 & 40 \\
$60-80$ tahun & 16 & 35,6 \\
$>80$ tahun & 1 & 2,2 \\
\hline Total & 45 & 100.0 \\
\hline
\end{tabular}

Tabel 2. Menunjukkan pasien yang terdiagnosa peritonitis perforasi paling banyak pada rentang usia 41-60 tahun dengan jumlah 18 orang (40\%).

Tabel 3. Karakteristik Pasien Peritonitis Perforasi Berdasarkan Etiologi Peritonitis perforasi

\begin{tabular}{lcc}
\hline Etiologi & Frekuensi (n) & Persentase (\%) \\
\hline Trauma tumpul abdomen & 8 & 17,7 \\
Trauma tajam abdomen & 5 & 11,2 \\
Appendisitis perforasi & 20 & 44,4 \\
Perforasi gaster & 12 & 26,7 \\
Komplikasi pasca tindakan operasi & 0 & 0 \\
\hline Total & 45 & 100.0 \\
\hline
\end{tabular}

Tabel 3. Menunjukkan appendisitis perforasi merupakan etiologi paling banyak menyebabkan peritonitis dengan jumlah 20 orang $(44,4 \%)$ diikuti dengan Perforasi gaster dengan jumlah 12 orang $(26,7 \%)$.

Tabel 4. Karakteristik pasien peritonitis Perforasi berdasarkan manifestasi klinis peritonitis perforasi

\begin{tabular}{lcc}
\hline Manifestasi klinis & Frekuensi (n) & Persentase (\%) \\
\hline Demam & 29 & 64,4 \\
Mual dan muntah & 33 & 73,3 \\
Distensi abdomen & 37 & 82,2 \\
Tidak dapat BAB & 31 & 68,8 \\
Nyeri perut & 45 & 100
\end{tabular}

Tabel 4. Menunjukkan manifestasi klinis paling banyak di derita oleh pasien peritonitis perforasi adalah nyeri tekan sebanyak 45 orang $(100 \%)$. 
Tabel 5. Karakteristik Pasien Peritonitis Perforasi Berdasarkan Tindakan Operatif

\begin{tabular}{lcc}
\hline Tindakan operatif & Frekuensi (n) & Persentase (\%) \\
\hline $\begin{array}{l}\text { Laparotomy eksplorasi } \\
\begin{array}{l}\text { Laparotomy eksplorasi dengan reseksi } \\
\text { dengan enterostomi (Jejunum dan Ileum) }\end{array}\end{array}$ & 13 & 28,9 \\
$\begin{array}{l}\text { Laparotomy eksplorasi dengan reseksi } \\
\text { dengan prosedur hartmann (Kolon) }\end{array}$ & 0 & 0 \\
$\begin{array}{l}\text { Laparotomy eksplorasi dengan } \\
\text { apendektomi (Apendiks) }\end{array}$ & 20 & 0 \\
$\begin{array}{l}\text { Laparotomy eksplorasi dengan eksisi } \\
\text { materi terinfeksi (Lambung) }\end{array}$ & 12 & 44,4 \\
\hline Total & 45 & 26,7 \\
\hline
\end{tabular}

Tabel 5. Menunjukkan tindakan operatif yang sering di lakukan adalah Laparotomy eksplorasi dengan apendektomi (Apendiks) sebanyak 20 orang (44,4\%).

Tabel 6. Karakteristik Pasien Peritonitis Perforasi Berdasarkan Post Operatif Komplikasi

\begin{tabular}{lcc}
\hline Post operatif komplikasi & Frekuensi (n) & Persentase (\%) \\
\hline Syok hipovolemik & 2 & 4,4 \\
Sepsis intra abdomen & 5 & 11,2 \\
Syok septik & 1 & 2,2 \\
Tidak ada komplikasi & 37 & 82,2 \\
\hline Total & 45 & 100.0 \\
\hline
\end{tabular}

Tabel 6. Menunjukkan bahwa sebanyak 37 orang (82,2\%) tidak mengalami komplikasi setelah tindakan operatif.

Tabel 7. Karakteristik Pasien Peritonitis Perforasi Berdasarkan Lama Rawatan

\begin{tabular}{lcc}
\hline Lama rawatan & Frekuensi (n) & Persentase (\%) \\
\hline 1-3 hari & 5 & 11,1 \\
4-7 hari & 24 & 53,4 \\
$8-12$ hari & 16 & 35,5 \\
\hline Total & 45 & 100.0 \\
\hline
\end{tabular}

Tabel 7. Menunjukkan bahwa lama rawatan pasien yang terdiagnosa peritonitis perforasi paling lama $4-7$ hari sebanyak 24 orang $(53,4 \%)$. 


\section{PEMBAHASAN}

1. Karakteristik pasien peritonitis perforasi berdasarkan jenis kelamin.

Hasil penelitian karakteristik pasien peritonitis berdasarkan jenis kelamin di BLUD Rumah Sakit Umum Cut Meutia Kabupaten Aceh Utara didapatkan data, laki-laki merupakan jenis kelamin tersering yang mengalami penyakit peritonitis perforasi sebanyak 30 orang $(66,6 \%)$.

Kepustakaan menyebutkan bahwa peritonitis dapat terjadi pada laki-laki maupun perempuan. ${ }^{(3)}$ Pada penelitian ini ditemukan bahwa laki-laki lebih sering terkena peritonitis dibandingkan perempuan. Hal ini sejalan dengan penelitian Sahu et al yaitu terdapat 44 pasien laki-laki dan 6 pasien perempuan dari 50 pasien. ${ }^{(7)}$ Penelitian oleh Singh et al dari Januari 2014-Maret 2015 juga didapatkan 45 laki-laki $(53,6 \%)$ dan 39 perempuan $(46,4 \%) .{ }^{(8)}$

2. Karakteristik pasien peritonitis perforasi berdasarkan usia

Hasil penelitian karakteristik pasien peritonitis berdasarkan usia di BLUD Rumah Sakit Umum Cut Meutia Kabupaten Aceh Utara didapatkan data, kelompok usia 40-60 tahun merupakan kelompok usia terbanyak yang mengalami peritonitis sebanyak 18 orang (40\%).

Kepustakaan tidak menyebutkan dengan pasti usia tersering seseorang terkena peritonitis. Kepustakaan menyebutkan bahwa peritonitis dapat mengenai semua usia. ${ }^{(9)}$ Usia pasien yang terkena peritonitis bervariasi menurut penelitian yang dilakukan oleh Mulari dan Leppaniemi di Finlandia dari September 2010-April 2012 didapatkan usia pasien tersering terkena peritonitis adalah 40-60 tahun. ${ }^{(7)}$

Hal ini dikarenakan pada kelompok usia 40-60 tahun, orang lebih besar kemungkinanya untuk megalami penyakit yang dapat menyebabkan peritonitis perforasi seperti appendicitis perforasi. ${ }^{(10)}$

3. Karakteristik pasien peritonitis perforasi berdasarkan etiologi Peritonitis perforasi

Hasil penelitian karakteristik pasien peritonitis berdasarkan usia di BLUD Rumah Sakit Umum Cut Meutia Kabupaten Aceh Utara didapatkan data, appendisitis perforasi merupakan penyebab tersering pasien terkena peritonitis perforasi sebanyak 20 orang (44,4\%). Hasil penelitian sejalan dengan penelitian Tawale et al dimana didapatkan etiologi tersering yang menyebabkan peritonitis perforasi adalah appendisitis perforasi sebanyak 80 orang $(51 \%)$ dan trauma abdomen sebanyak 27 orang $(21 \%) .{ }^{(8)}$ hal ini dapat dijelaskan sebagai pasien yang datang cenderung dengan keluhan appendisitis dan sudah mengalami perforasi yang memicu terjadinya peritonitis perforasi. ${ }^{(10)}$ 
4. Karakteristik pasien peritonitis perforasi berdasarkan manifestasi klinis peritonitis perforasi

Hasil penelitian karakteristik pasien peritonitis berdasarkan usia di BLUD Rumah Sakit Umum Cut Meutia Kabupaten Aceh Utara didapatkan data, nyeri perut merupakan gejala yang pasti dialami oleh pasien peritonitis sebanyak 45 orang (100\%). Hasil penelitian pada 87 pasien yang dilakukan oleh Nadia dan Risna di RSUD Arifin Achmad Provinsi Riau menunjukan bahwa seluruh pasien dengan peritonitis perforasi mengalami nyeri perut ${ }^{(11)}$ Tidak hanya nyeri perut, sulit untuk bab juga sering di keluhkan oleh pasien. Nyeri perut ini timbul karena respon dari peradangan yang terjadi di daerah abdomen dan bab yang sulit untuk keluar dikarenakan peradangan sudah menginvasi usus sehingga menganggu pergerakan dari usus tersebut. ${ }^{(5)}$

5. Karakteristik pasien peritonitis perforasi berdasarkan tindakan operatif

Hasil penelitian karakteristik pasien peritonitis berdasarkan usia di BLUD Rumah Sakit Umum Cut Meutia Kabupaten Aceh Utara didapatkan data, laparotomy eksplorasi dengan apendektomi (Apendiks) merupakan tindakan yang sering dilakukan kepada 20 orang (44,4\%). Hasil penelitian di atas hampir sama dengan penelitian yang dilakukan oleh Lukman dan Siddiq di RSUP H. Adam Malik, pada penelitian tersebut tindakan operatif yang sering dilakukan hanya lah laparotomi sebanyak 37 orang (41\%) dan laparotomy eksplorasi dengan apendektomi sebanyak 17 orang (19\%). ${ }^{(12)}$

Tindakan operasi yang dilakukan tergantung dari penyakit penyerta yang menyebabkan terjadinya peritonitis perforasi, sehingga dengan tindakan yang tepat dapat pula meningkatkan prognosa yang baik bagi pasien. ${ }^{(13)}$

6. Karakteristik pasien peritonitis perforasi berdasarkan post operatif komplikasi

Hasil penelitian karakteristik pasien peritonitis berdasarkan usia di BLUD Rumah Sakit Umum Cut Meutia Kabupaten Aceh Utara didapatkan data, tidak ada komplikasi yang berarti dalam tindakan operatif yang telah dilakukan terhadap 37 orang (82,2\%). Hasil penelitian yang dilakukan oleh Tami et al di Rumah Sakit Advent Bandar Lampung juga menunjukan bahwa sebanyak 31 orang (73\%) tidak mengalami komplikasi yang berarti dan sebanyak 2 orang $(4,7 \%)$ mengalami shock hipovolemik. ${ }^{(9)}$ Komplikasi post operatif bedah sering kali menjadi salah satu menjadi kecemasaan pasien, namun dengan tindakan operatif yang sesuai dan di tangani oleh ahli, komplikasi tersebut dapat di minimalisir ${ }^{(14)}$ 
7. Karakteristik pasien peritonitis perforasi berdasarkan lama rawatan

Hasil penelitian karakteristik pasien peritonitis berdasarkan usia di BLUD Rumah Sakit Umum Cut Meutia Kabupaten Aceh Utara didapatkan data, 4-7 hari merupakan waktu yang dibutuhkan untuk pasien sebanyak 24 orang $(53,4 \%)$ pulih. Hasil penelitian di atass sejalan dengan penelitian yang dilakukan oleh Nugroho Budi Utomo RS Cipto Mangunkusumo yang dilakukan pada 50 responden pasien peritonitis perforasi, di dapatkan rata-rata lama rawatan pasien pasca operasi adalah $4-8$ hari sebanyak $(32 \%) .{ }^{(9)}$ Lama rawatan tergantung kepada penyakit dan komplikasi penyerta setelah dilakukannya operasi, waktu 4-8 hari adalah waktu yang dibutuhkan untuk pasien dapat sembuh pasca operasi. Namun jika masih memiliki penyakit penyerta lama rawatan seseorang pasca operasi dapat mencapai 812 hari. $^{(15)}$

\section{KESIMPULAN}

1. Karakteristik pasien peritonitis perforasi di BLUD Rumah Sakit Umum Cut Meutia Kabupaten Aceh Utara, berdasarkan jenis kelamin terbanyak berada pada kelompok lakilaki sebanyak 30 orang $(66,6 \%)$.

2. Karakteristik pasien peritonitis perforasi di BLUD Rumah Sakit Umum Cut Meutia Kabupaten Aceh Utara, berdasarkan usia terbanyak berada pada kelompok usia 40-60 tahun sebanyak 18 orang $(40 \%)$.

3. Karakteristik pasien peritonitis perforasi berdasarkan etiologi Peritonitis perforasi di BLUD Rumah Sakit Umum Cut Meutia Kabupaten Aceh Utara, terbanyak ialah appendisitis perforasi sebanyak 20 orang $(44,4 \%)$.

4. Karakteristik pasien peritonitis perforasi berdasarkan manifestasi klinis di BLUD Rumah Sakit Umum Cut Meutia Kabupaten Aceh Utara, terbanyak ialah nyeri perut sebanyak 45 orang $(100 \%)$.

5. Karakteristik pasien peritonitis perforasi berdasarkan tindakan operatif di BLUD Rumah Sakit Umum Cut Meutia Kabupaten Aceh Utara, terbanyak ialah Laparotomy eksplorasi dengan apendektomi sebanyak 20 orang $(44,4 \%)$.

6. Karakteristik pasien peritonitis perforasi berdasarkan post operatif komplikasi di BLUD Rumah Sakit Umum Cut Meutia Kabupaten Aceh Utara menujukan bahwa tidak ada komplikasi yang berarti pada pasien sebanyak 37 orang $(82,2 \%)$.

7. Karakteristik pasien peritonitis perforasi berdasarkan lama rawatan di BLUD Rumah Sakit Umum Cut Meutia Kabupaten Aceh Utara menunjukan 4-7 hari merupakan waktu yang dibutuhkan untuk pasien pulang sebanyak 24 orang $(53,4 \%)$. 


\section{SARAN}

1. Perlunya penelitian lebih lanjut mengenai faktor-faktor lain yang memengaruhi mengenai efek dari terapi oral yang di berikan terhadap kesembuhan pasien.

2. Bagi peneliti lainnya agar dapat melakukan penelitian lebih lanjut mengenai peritonitis perforasi dengan menggunakan metode penelitian yang berbeda, sampel yang lebih banyak, dan dengan tempat penelitian yang lebih luas.

3. Bagi BLUD Rumah Sakit Umum Cut Meutia Kabupaten Aceh Utara diharapkan dapat melengkapi data terkait pasien peritonitis perforasi guna meningkatkan kelengkapan rekam medik.

\section{REFERENSI}

1. Arief M. Bedah Digestif, dalam Kapita Selekta Kedokteran. 3rd ed. Jakarta: Media Aesculapius FKUI; 2009. 21 p.

2. Jong W de, Sjamsuhidayat.R. Gawat Abdomen, dalam Buku ajar Ilmu Bedah. Jakarta: ECG; 2011.212 p.

3. Paryani J. Etiology of peritonitis and factors predicting the mortality in peritonitis. NJCM. 2014;4.

4. Departeme K. Profil pasien peritonitis di indoensia. Dep Kesehat. 2012;7.

5. Marshall JC. Current focus. Intra-abdominal infections. Elsevier. 2007;6.

6. Ordonez CA, Puyana JC. Management of peritonitis in the critically ill patient. Surg Clin North Am. 2009;2.

7. Agarwal S. Prediction of outcome using the mannheim peritonitis index in cases of peritonitisPrediction of outcome using the mannheim peritonitis index in cases of peritonitis. Evid Based Med Hlthcare. 2016;2.

8. Lopez N. A comprehensive review of abdominal infections. WJES. 2013;

9. LR M, J B. Clinical study and management of secondary peritonitis due to perforated hollow viscus. Arch Med. 2009;12.

10. Chalya P. Clinical profile and outcome of surgical treatment of perforated peptic ulcer in northwestern tanzania. Tert Hosp Exp. 2012;14.

11. Schrock TR. Peritonitis dan Massa abdominal dalam IlmuBedah. 7th ed. Jakarta: ECG; 2014. 40 p.

12. J.A.Lee. Peritonitis secondary. Div Surg. 11th ed. 2012;221.

13. Fauci. Harrisons Principle of Internal Medicine. Mc Graw Hill. 2014;12:34.

14. Debas H. Gastrointestinal Surgery. USA: Springer; 2011.

15. Baroni G. Inflamation and the peritoneal membrane: causes and impact on structure and function during peritoneal dialysis. Mediat Inflamations. 2014;4. 